\title{
Experimental and numerical study on the influence of critical 3D printing processing parameters
}

\author{
Nikoletta Chatzidai, Dimitrios Karalekas \\ University of Piraeus, Laboratory of Advanced Manufacturing Technologies and Testing, Department of Industrial Management \\ and Technology \\ nchatri@unipi.gr;dkara@unipi.gr;dkara@webmail.unipi.gr;
}

\begin{abstract}
In the present work the temperature profile variations generated in rectangular specimens built using the Fused Deposition Modeling (FDM) process, at different printing speeds and orientations, were investigated. The temperature recordings were achieved by the integration of temperature sensors throughout the $1^{\text {st }}$ and/or $21^{\text {st }}$ building layer of the specimens. The experimental results show that the temperature values inside the specimen remain above the glass transition temperature $\left(\mathrm{T}_{\mathrm{g}}\right)$ even at the end of the fabrication process. Higher values were obtained when increasing the printing speed and decreasing the printing path. The experimental results were compared to the corresponding ones derived by simulation of the thermal diffusion problem via Finite Element Analysis. The calculated maximum temperature values were in good agreement with the experimentally recorded ones.
\end{abstract}

KEYWORDS. Additive manufacturing; Fused deposition modelling; Process parameters; Temperature profiles; Finite element analysis.

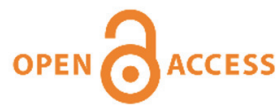

Citation: Chatzidai, N., Karalekas, D., Experimental and numerical study on the influence of critical 3D printing processing parameters, Frattura ed Integrità Strutturale, 50 (2019) 407-413.

Received: 18.01.2019

Accepted: 21.05.2019

Published: 01.10.2019

Copyright: (C) 2019 This is an open access article under the terms of the CC-BY 4.0, which permits unrestricted use, distribution, and reproduction in any medium, provided the original author and source are credited.

\section{INTRODUCTION}

\footnotetext{
A dditive manufacturing (AM) or layer manufacturing (LM) have developed intensively over the last decades, providing the potentiality to build simple or more complex $3 \mathrm{D}$ objects of varying material types and forms. As defined by the ASTM:F2792-12a (2012) standard, additive manufacture is the "process of joining materials to make objects from 3D model data, usually layer upon layer, as opposed to subtractive manufacturing methodologies, such as traditional machining". AM techniques are gaining ground in industries, since their ability to make the manufacturing and the assembly process less complicated help to shorten the product development cycle time.

Fused Deposition Modeling (FDM) is one of the several existing technologies included in the category of the AM techniques. It became popular due to its low cost, easy operation and reproducibility [1]. As described in previous works [2-5], the FDM method deposits rasters of molten thermoplastic polymers, such as Acrylonitrile Butadiene Styrene (ABS) or Polylactic Acid (PLA), that solidify into the final desired shape. During the fabrication process, filament of the thermoplastic material is fed into a heated extrusion tip, where it liquefies above its glass transition temperature $\left(\mathrm{T}_{\mathrm{g}}\right)$, and
} 
extruded as thin rasters through a nozzle onto the build platform to form the first layer [6,7]. The next material layer is deposited upon the previous one, while the process is continued to form the final desired model [8]. After its deposition, the extruded material rapidly cools, solidifies, and bonds with the surrounding material [9]. As long as the material is hot (above $\mathrm{T}_{\mathrm{g}}$ ) it can bond with the previous layer or the adjacent rasters. The bonding mechanism no longer takes place once the material cools below its $T_{g}$. Therefore, the longer the material is kept above its $T_{g}$, the better the bond between layers and rastres [10]. On the other hand, the deposited material should solidify as quickly as possible to avoid deformation due to gravity, or weight of the above deposited material [11]. Moreover, the non-uniform thermal gradients that exhibit during the FDM process, develop residual stresses which may induce warping and delamination $[12,13]$ or even part distortions, dimension inaccuracy or part fabrication failure [9]. As a result, the knowledge of temperature evolution during the component's fabrication process is one of the primary concerns in FDM process.

The quality, accuracy and properties of the final printed parts depend also on other user control process parameters, such as build orientation, layer thickness, infill density, raster angle, extruder temperature and air gap between adjacent rasters. A lot of research has done the last two decades on the influence of the printing process parameters on the mechanical properties of the printed parts [3,7,14-24] and/or the bonding degree between the rasters [3,20,22,25-28]. Sood et al. [22, 27] examined five important process parameters (layer thickness, orientation, raster angle, raster width and air gap) both experimentally and numerically, and showed that they do not work alone, but interact during the FDM process and influence the tensile and compressive strength of the final part.

Besides the effect of the process parameters on the mechanical properties of the final object, particular interest has shown by researchers on the temperature field and the related temperature gradient as a result of different process conditions. Sun et al. $[20,29]$ tried to correlate important process parameters with the quality of bond formation via temperature measurements in the bottom layer of an FDM fabricated component. Zhang and Chou [30] considered the influence of tool-path on temperature variation to explain thermo-mechanical distortion through residual stress distribution. More recently, Costa et al. [31] examined the contribution of various thermal phenomena developing during fused deposition techniques to the overall heat transfer and to the mechanical deformation of the fabricated parts. Later, the same authors [11], presented an analytical solution for the transient heat transfer during filament deposition and cooling considering four main process parameters (extrusion velocity, filament dimensions, sequence of deposition and environmental temperature). Zhang et al. [32] used the boundary-adjusting finite difference method to adapt a three-dimensional transient mathematical model to describe the influence of various process parameters on the temperature variation of any FDM printed cuboid specimen. $\mathrm{Li}$ et al. [33], studied experimentally the effect of major process parameters, such as layer thickness, deposition velocity and infill rate, on the bonding degree between the rasters, on the temperature profiles during the FDM process and on product's mechanical properties. In that work, the experimental process was conducted for a component made from PLA using an open-source MakerBot FDM printer.

In the present study, the real-time temperature profiles of rectangular specimens were investigated, under different printing velocities and raster orientations. The recording of the temperature values was achieved through the integration of temperature sensors in various layers of the printed specimens. The experimental results were compared to those derived by Finite Element Analysis.

\section{EXPERIMENTAL PROCEDURE}

$\mathrm{R}$ ectangular specimens of commercial thermoplastic Acrylonitrile Butadiene Styrene (ABS) were built on the MakerBot Replicator 2X FDM Printer. The dimensions of the specimens were $40 \mathrm{~mm}$ x $20 \mathrm{~mm}$ and consisted of 41 layers. The thickness of each layer was $0.254 \mathrm{~mm}$. The advantage of a such an opensource FDM printer is the ability of changing a large number of building parameters, such as printing speed, layer thickness, density of the rasters (infill density), building orientation and temperature of the printing heads. In the present study, all the above parameters remained constant, besides the building orientation and the printing speed.

Temperature sensors (K-type thermocouples, $\pm 1.5^{\circ} \mathrm{C}$ ) were embedded at the center of the $1^{\text {st }}$ and/or the $21^{\text {st }}$ building layer, for the recording of the temperature variations throughout the building process and until the completion of the specimens' fabrication. This type of sensors has a sensing tip of $0.25 \mathrm{~mm}$ thickness. The temperature data recordings were obtained and analyzed through a data acquisition instrument. The embedment of the thermocouples was carried out manually. Special retainers were designed and built simultaneously with the specimen to assure the integration of the sensors at the desired positions.

The building process of the 3D printed rectangular specimen started with deposition of a raft of small thickness, made of polystyrene to increase the contact surface between the specimen and the platform. This polystyrene raft was considered 
necessary since the temperature on the building platform was $20-25^{\circ} \mathrm{C}$ below the one that was setup initially, causing the detachment of the specimen. Once this raft was completed, deposition of the ABS material was started. Initially, at each layer, two shells that delimit the specimen were built, and thereafter the internal raster-by-raster material deposition was initiated. The building process continued until the plane at which the thermocouple had to be integrated was reached. At that point, the building process was paused temporally, to integrate the thermocouple, and then continued until the completion of the specimen fabrication. In the case that two thermocouples were integrated in different layers, the building process was paused twice. Images of the specimens are shown in Fig.1.

(a)

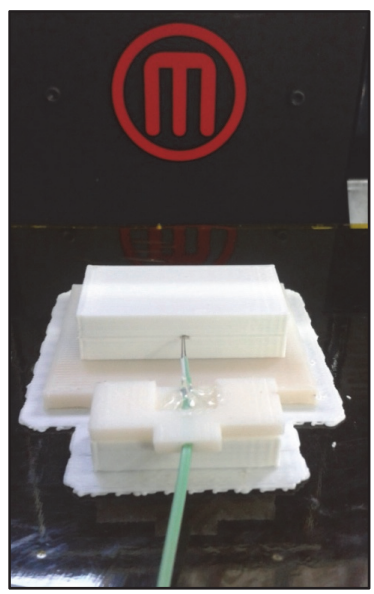

(b)

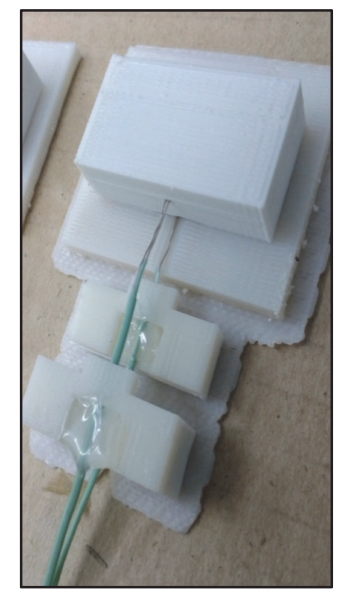

Figure 1: Specimen with thermocouple in the (a) $21^{\text {st }}$ layer and (b) $1^{\text {st }}$ and $21^{\text {st }}$ layer.

As shown in Table 1, specimens were built with two different building speeds (35 sec/layer and 65 sec/layer) and building orientations $\left(0^{\circ}\right.$ and $\left.90^{\circ}\right)$. The orientation of the building process is prescribed according to the specimen's physical coordinate system, as shown in Fig. 2.

\begin{tabular}{cccc}
\hline Specimen & $\begin{array}{c}\text { Building } \\
\text { orientation }\end{array}$ & $\begin{array}{c}\text { Building speed } \\
(\mathrm{sec} / \text { layer })\end{array}$ & $\begin{array}{c}\text { Layer of the embedded } \\
\text { thermocouple }\end{array}$ \\
1 & $0^{\circ}$ & 35 & 1 \\
3 & $0^{\circ}$ & 35 & 21 \\
4 & $0^{\circ}$ & 35 & 1 and 21 \\
5 & $0^{\circ}$ & 65 & 21 \\
& $90^{\circ}$ & 65 & 21 \\
\hline
\end{tabular}

Table 1: Specimens and their building parameters.

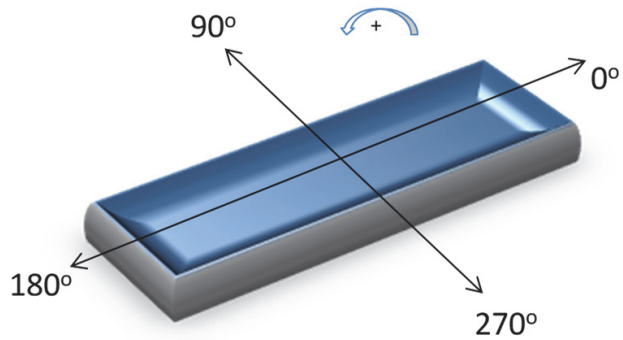

Figure 2: Physical coordinate system of the rectangular specimen.

For all the specimens, the infill density was set up to 0.9 for greater adhesion. The liquefier temperature of the extruded material was set up at $230^{\circ} \mathrm{C}$, since higher temperatures caused burning of the material. Additionally, it deemed necessary to measure the envelope temperature, since it can't be controlled automatically by the 3D printer software. The temperature was found to be $85^{\circ} \mathrm{C}$. 


\section{FINITE ELEMENT MODELING}

he simulation of the thermal diffusion problem in rectangular specimens during the FDM building process was carried out using the ABAQUS ${ }^{\circledR}$ software (ABAQUS, Hibbitt, Karlsson \& Sorensen, Inc., RI, USA). The simulation procedure was conducted in the following stepwise manner:

Step 1. A rectangular model was designed with dimensions $40 \mathrm{~mm}$ x $20 \mathrm{~mm}$ x $0.254 \mathrm{~mm}$ (length x width $\mathrm{x}$ height) for specimen 1 and $40 \mathrm{~mm}$ x $20 \mathrm{~mm}$ x $5.334 \mathrm{~mm}$ (length $\mathrm{x}$ width $\mathrm{x}$ height) for specimens 2, 4 and 5. This model represents the part of the specimen that the thermocouple was integrated.

Step 2. A new model, with $n l \times 0.254 \mathrm{~mm}$ height was designed at the top of the previous one, where $n l=1, \ldots, 40$ for specimen 1 and $n l=1, \ldots, 20$ for specimens 2, 4 and 5. This model represents the new ABS layers.

Each time, both models were meshed and solved, using the equations and the boundary conditions that are presented further down. The temperatures calculated from the numerical solution of the equations, correspond to the time that the extruder passes above the sensor. The governing equation for the thermal analysis of the rectangular specimen is given by:

$$
\frac{\partial\left(\rho c_{p} T\right)}{\partial t}=\nabla \cdot k \nabla T+q
$$

where $T$ is the temperature, $\varrho$ the density, $C_{p}$ the specific heat, $k$ the thermal conductivity and $q$ the heat generation rate. The thermal properties of the ABS material that used for the simulations are shown in Table 2 [20].

\begin{tabular}{cc}
\hline Parameter & Values \\
Thermal conductivity, $k$ & $0.177 \mathrm{~W} / \mathrm{m} \cdot \mathrm{K}$ \\
Specific heat, $C_{p}$ & $2.080 \mathrm{~J} / \mathrm{kg} \cdot \mathrm{K}$ \\
Density, $\varrho$ & $1.050 \mathrm{~kg} / \mathrm{m}^{3}$ \\
\hline
\end{tabular}

Table 2: Thermal properties of the ABS material.

At the outer surfaces of the rectangular specimen, the equation of convection was set as boundary condition:

$$
Q=h\left(T-T_{\text {env }}\right)
$$

where $h$ is the heat convection coefficient, that was taken equal to $75 \mathrm{~W} / \mathrm{m}^{2} \cdot \mathrm{K}$ [9], and $T_{e n v}$ the temperature of the chamber, equal to $85^{\circ} \mathrm{C}$, as measured experimentally.

The temperature at the bottom surface of the rectangular specimen is set to be constant and equal to $88^{\circ} \mathrm{C}$, the temperature on the polystyrene raft. This is a mean value obtained by the integration of a thermocouple between the polystyrene raft and the $1^{\text {st }}$ ABS layer. For the upper surface of the rectangular specimen, a known temperature profile is used as boundary condition. This temperature profile was derived by the experimental data, during the first pass of the printing nozzle over the thermocouple.

For the FE simulations, the modeled specimen was considered to be solid, while the raster orientation and possible abnormalities or discontinuities of the experimental process were not taken into account.

\section{RESULTS AND DISCUSSION}

I n Figs.3(a,b) the obtained experimental temperature profiles for specimens 1-2 (see Table 1) are shown, as a function of building time. The building orientation $\left(0^{\circ}\right)$ and speed $(35 \mathrm{sec} /$ layer) remain the same for the two specimens. Moreover, in the same figures the temperature peak values calculated by the finite element analysis are also plotted. In these figures, and those that follow, the curves represent the real-time monitoring temperature variations that take place during the fabrication process, while their peaks correspond to the time that the printer's nozzle passes over the integrated thermocouple.

In Fig.3a (specimen 1), the temperature profile that developed during the deposition of the 1 st layer is shown, and all the subsequent layers, until the completion of the specimen's fabrication. As it was expected, the greater temperature values are shown right after the integration of the thermocouple since it is in direct contact with the deposited material. Each peak 


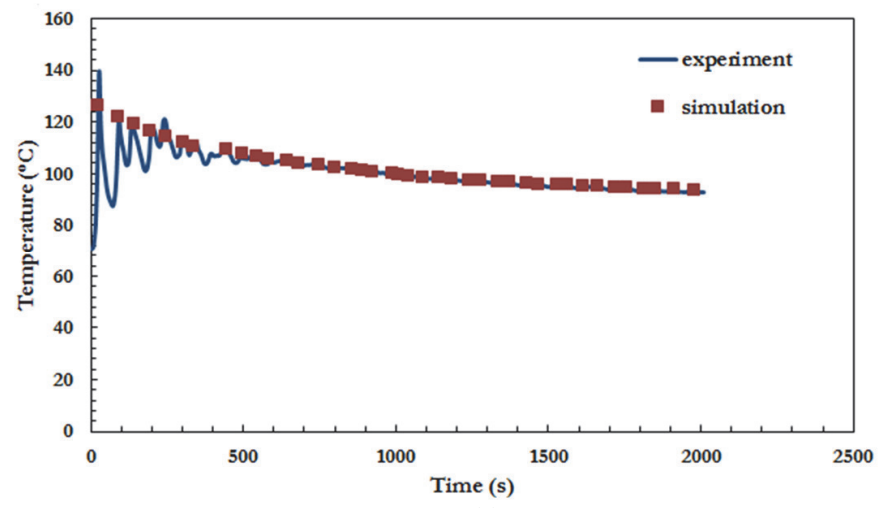

(a)

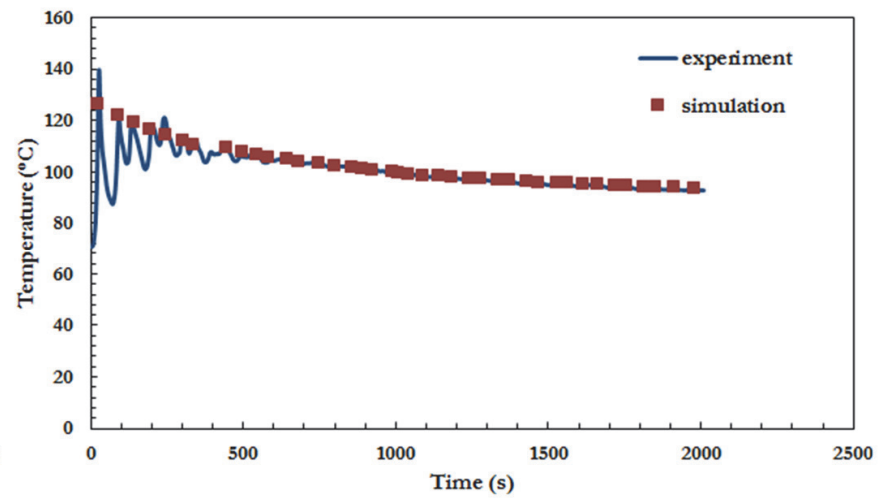

(b)

Figure 3: Temperature profiles as recorded by thermocouples together with the temperature peak values as calculated by FEA for embedding locations: (a) $1^{\text {st }}$ layer and (b) $21^{\text {st }}$ layer.

is followed by a rapid decrease in the temperature. The temperature profile shows a declining pattern with time. However, it is obvious that the temperature profile is fluctuating, with gradually lower maxima even when the fabrication of the specimen is well above the $1^{\text {st }}$ layer. At the end of the printing process the temperature at the first layer exhibits a value of $93^{\circ} \mathrm{C}$ (due to the heat generated by the heated platform) which is very close to the glass transition temperature $\left(\mathrm{T}_{\mathrm{g}}\right)$. For $\mathrm{ABS}$ the $\mathrm{T}_{\mathrm{g}}$ is $94^{\circ} \mathrm{C}$. This shows the importance of heat transfer through conduction within the structure.

In Fig. $3 \mathrm{~b}$ the temperature profiles as a function of building time in the case of specimen 2 are presented. The thermocouple was integrated in $21^{\text {st }}$ layer, so the reordered data refers to only half the specimen (21 layers). It is seen that the temperature profile is similar to the one presented in Fig.3a, while the effect of the printing nozzle is more intense at the layers deposited at the end of the printing process.

In Fig. 4 the temperature data of specimen 3 are shown. In this case two thermocouples were integrated in the same specimen, one at $1^{\text {st }}$ layer and the other at the $21^{\text {st }}$ layer. The exhibited recording presents a similarity to the previously presented experimental data. The sudden temperature drop recorded by the thermocouple integrated in the first layer shows the time that the building process was paused temporarily for the integration of the $2^{\text {nd }}$ thermocouple.

In Figs.5(a,b) the temperature profiles for specimens 4 and 5 of Table 1 are shown. These specimens were built with higher printing speed (65 sec/layer), compared to the previous ones. The recorded temperature profile is similar to the corresponding ones of the previous specimens, but the temperature values remain higher and well above $\mathrm{T}_{\mathrm{g}}$. This suggests that the adjacent rasters have more time to bond. The higher speed of the printing nozzle contributes to the maintenance of the higher temperatures inside the specimen. Additionally, the printing speed together with the shorter toolpath of the printing nozzle (specimen 5, Fig.5b), allow for a more uniform temperature profile inside the specimen. The irregularities observed for the temperature profile at the first four layers of the 3D printed rectangular specimen are likely to be due to possible levitation of the embedded thermocouple.

As far as the simulated temperature profiles are concerned, they are in good agreement with the experimental ones, especially for specimens 4 and 5. Increasing the speed of the printing nozzle, and even more in the case of shorter build path (specimen

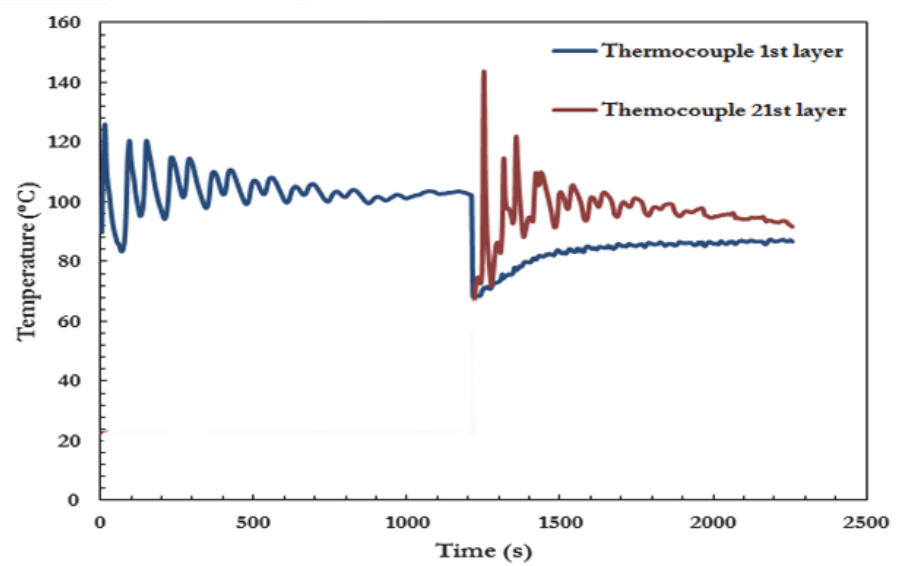

Figure 4: Temperature profiles as recorded by the two thermocouples integrated in $1^{\text {st }}$ and $21^{\text {st }}$ layer. 


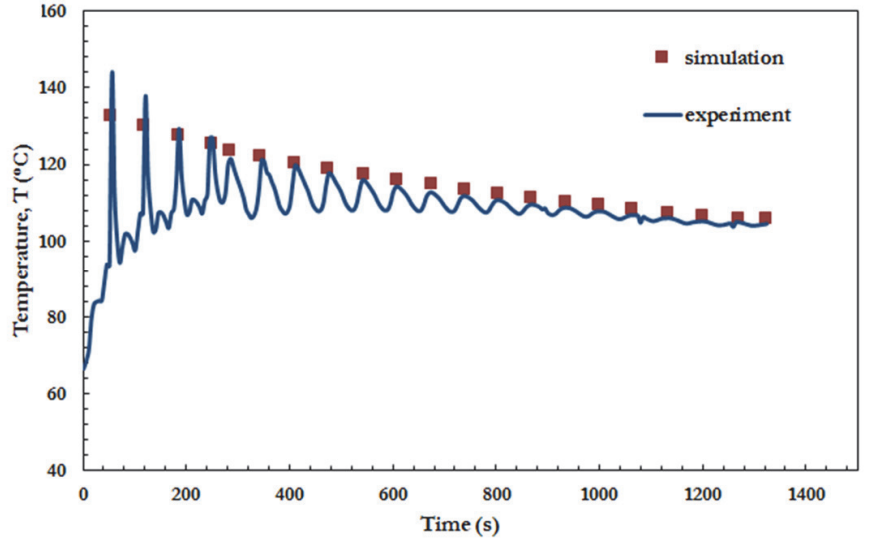

(a)

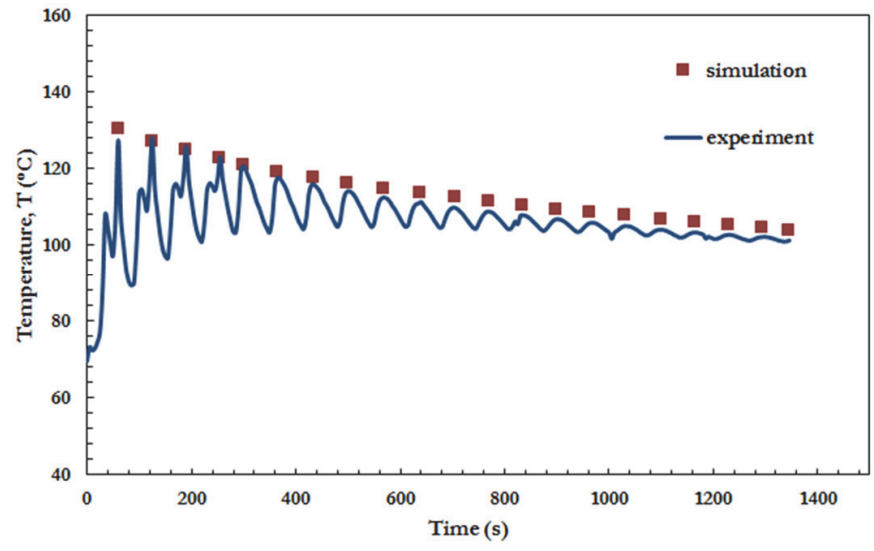

(b)

Figure 5: Temperature profiles as recorded by thermocouples integrated in $21^{\text {st }}$ layer together with the temperature peak values for: (a) $0^{\circ}$ and (b) $90^{\circ}$ raster orientation.

5), ensures greater bonding of the rasters within the fabricated specimen, and thus, approaching the ideal theoretical solid model that was used to perform the simulations. On the other hand, the differences between the experimental and the simulated temperature profiles of Figs. $3(\mathrm{a}, \mathrm{b})\left(\max 5^{\circ} \mathrm{C}\right)$, show that the gaps between the rasters should be taken into account.

\section{CONCLUSIONS}

$\mathrm{I}$ $\mathrm{n}$ the present work 3D printed rectangular polymer specimens were fabricated under different building speeds and orientations. Temperature sensors were integrated throughout the center of the $1^{\text {st }}$ and $/$ or $21^{\text {st }}$ building layer of these specimens to investigate the temperature profiles generated during the fabrication process. The experimentally obtained results were compared to the corresponding ones derived by the thermal diffusion finite element analysis.

The experimental results demonstrate an undulated temperature profile with a declining pattern. Higher rates of the printing nozzle in conjunction with shorter printing path lead to the preservation of higher temperature values inside the specimen. The thermal behavior of the specimen is influenced both by the extruded material and the heated printing platform even during the end at the printing process.

The simulation based calculated maximum temperature values exhibit good agreement, in general, with the experimentally measured ones, presenting a maximum difference of $5^{\circ} \mathrm{C}$. However, by increasing the printing speed and decreasing the printing tool-path the rasters' bonding enhances leading to a more solid 3D printed specimen which approaches the ideal model considered in the FEM analysis.

\section{REFERENCES}

[1] Chua, C.K., Leong, K.F., Lim, C.S. (2010). Rapid Prototyping, Principles and Applications, World Scientific.

[2] Coogan, T.J., Kazmer, D.O. (2017). Bond and part strength in fused deposition modeling, Rapid Prototyp. J., 23(2), pp. 248-257, DOI: 10.1108/RPJ-03-2016-0050.

[3] Ahn, S., Montero, M., Odell, D., Roundy, S., Wright, P.K. (2002). Anisotropic material properties of fused deposition modeling ABS, Rapid Prototyp. J., 8(4), pp. 248-257, DOI: 10.1108/13552540210441166.

[4] Bellini, A., Güçeri, S. (2003). Mechanical characterization of parts fabricated using fused deposition modeling, Rapid Prototyp. J., 9(4), pp. 252-264, DOI: 10.1108/13552540310489631.

[5] Bellehumeur, C., Li, L., Sun, Q., Gu, P. (2004). Modeling of bond formation between polymer filaments in the fused deposition modeling process, J. Manuf. Process., 6(2), pp. 170-78, DOI: 10.1016/S1526-6125(04)70071-7.

[6] Shofner, M.L., Lozano, K., Rodríguez-Macías, F.J., Barrera, E. V. (2003). Nanofiber-reinforced polymers prepared by fused deposition modeling, J. Appl. Polym. Sci., 89(11), pp. 3081-3090, DOI: 10.1002/app.12496.

[7] Es-Said, O.S., Foyos, J., Noorani, R., Mendelson, M., Marloth, R., Pregger, B.A. (2000). Effect of Layer Orientation on Mechanical Properties of Rapid Prototyped Samples, Mater. Manuf. Process., 15(1), pp. 107-122, DOI: $10.1080 / 10426910008912976$. 
[8] Giordano, R.A., Wu, B.M., Borland, S.W., Cima, L.G., Sachs, E.M., Cima, M.J. (1996). Mechanical properties of dense polylactic acid structures fabricated by three dimensional printing. J. Biomater. Sci. Polym. Ed., 8(1), pp. 63-75.

[9] Kousiatza, C., Chatzidai, N., Karalekas, D. (2017). Temperature Mapping of 3D Printed Polymer Plates: Experimental and Numerical Study, Sensors, 17(3), pp. 456, DOI: 10.3390/s17030456.

[10] Dinwiddie, R.B., Kunc, V., Lindal, J.M., Post, B., Smith, R.J., Love, L., Duty, C.E. (2014). Infrared Imaging of the Polymer 3D-Printing Process, Proc. of SPIE, 9105, 910502-1, DOI: 10.1117/12.2053425.

[11] Costa, S.F., Duarte, F.M., Covas, J.A. (2017). Estimation of filament temperature and adhesion development in fused deposition techniques, J. Mater. Process. Technol., 245, pp. 167-179, DOI: 10.1016/j.jmatprotec.2017.02.026.

[12] Kantaros, A., Karalekas, D. (2013). Fiber Bragg grating based investigation of residual strains in ABS parts fabricated by fused deposition modeling process, Mater. Des., 50, pp. 44-50, DOI: 10.1016/j.matdes.2013.02.067.

[13] Kousiatza, C., Karalekas, D. (2016). In-situ monitoring of strain and temperature distributions during fused deposition modeling process, JMADE, 97, pp. 400-406, DOI: 10.1016/j.matdes.2016.02.099.

[14] Rayegani, F., Onwubolu, G.C. (2014). Fused deposition modelling (FDM) process parameter prediction and optimization using group method for data handling $(\mathrm{GMDH})$ and differential evolution (DE), Int. J. Adv. Manuf. Technol., 73(1-4), pp. 509-519, DOI: 10.1007/s00170-014-5835-2.

[15] Huang, B., Singamneni, S. (2015). Raster angle mechanics in fused deposition modelling, J. Compos. Mater., 49(3), pp. 363-383, DOI: 10.1177/0021998313519153.

[16] Yan, Y., Zhang, R., Hong, G., Yuan, X. (2000). Research on the bonding of material paths in melted extrusion modeling, Mater. Des., 21(2), pp. 93-99, DOI: 10.1016/S0261-3069(99)00058-8.

[17] Rezayat, H., Zhou, W., Siriruk, A., Penumadu, D., Babu, S.S. (2015). Structure-mechanical property relationship in fused deposition modelling, Mater. Sci. Technol., 31(8), pp. 895-903, DOI: 10.1179/1743284715Y.0000000010.

[18] Rodríguez, J.F., Thomas, J.P., Renaud, J.E. (2003). Mechanical behavior of acrylonitrile butadiene styrene fused deposition materials modeling, Rapid Prototyp. J., 9(4), pp. 219-230, DOI: 10.1108/13552540310489604.

[19] Ahn, S.H., Baek, C., Lee, S., Ahn, I.S. (2003). Anisotropic Tensile Failure Model of Rapid Prototyping Parts - Fused Deposition Modeling (FDM), Int. J. Mod. Phys. B, 17(8-9), pp. 1510-1516, DOI: 10.1142/S0217979203019241.

[20] Sun, Q., Rizvi, G.M., Bellehumeur, C.T., Gu, P. (2008). Effect of processing conditions on the bonding quality of FDM polymer filaments, Rapid Prototyp. J., 14(2), pp. 72-80, DOI: 10.1108/13552540810862028.

[21] Luzanin, O., Movrin, D., Plancak, M. (2014). Effect of layer thickness, deposition angle, and infill on maximum flexural force in FDM-built specimens, J. Technol. Plast., 39(1), pp. 49-58.

[22] Sood, A.K., Ohdar, R.K., Mahapatra, S.S. (2012). Experimental investigation and empirical modelling of FDM process for compressive strength improvement, J. Adv. Res., 3, pp. 81-90, DOI: 10.1016/j.jare.2011.05.001.

[23] Boschetto, A., Bottini, L., Veniali, F. (2016). Integration of FDM surface quality modeling with process design, Addit. Manuf., 12, pp. 334-344, DOI: 10.1016/j.addma.2016.05.008.

[24] Lee, B.H., Abdullah, J., Khan, Z.A. (2005). Optimization of rapid prototyping parameters for production of flexible ABS object, J. Mater. Process. Technol., 169, pp. 54-61, DOI: 10.1016/j.jmatprotec.2005.02.259.

[25] Gurrala, P.K., Regalla, S.P. (2014). Part strength evolution with bonding between filaments in fused deposition modelling, Virtual Phys. Prototyp., 9(3), pp. 141-149, DOI: 10.1080/17452759.2014.913400.

[26] Magalhães, L.C., Volpato, N., Luersen, M.A. (2014). Evaluation of stiffness and strength in fused deposition sandwich specimens, J. Brazilian Soc. Mech. Sci. Eng., 36(3), pp. 449-459, DOI: 10.1007/s40430-013-0111-1.

[27] Sood, A.K., Ohdar, R.K., Mahapatra, S.S. (2010). Parametric appraisal of mechanical property of fused deposition modelling processed parts, Mater. Des., 31, pp. 287-295, DOI: 10.1016/j.matdes.2009.06.016.

[28] Abbott, A.C., Tandon, G.P., Bradford, R.L., Koerner, H., Baur, J.W. (2018). Process-structure-property effects on ABS bond strength in fused filament fabrication, Addit. Manuf., 19, pp. 29-38, DOI: 10.1016/j.addma.2017.11.002.

[29] Sun, Q., Rizvi, G.M., Bellehumeur, C.T. and Gu, P., 2003, August. Experimental study of the cooling characteristics of polymer filaments in FDM and impact on the mesostructures and properties of prototypes. In Proceedings of the 14th Solid Freeform Fabrication Symposium, Austin, pp. 313-323.

[30] Zhang, Y., Chou, Y. (2006). Three-dimensional finite element analysis simulations of the fused deposition modelling process, Proc. Inst. Mech. Eng. Part B J. Eng. Manuf., 220(10), pp. 1663-1671, DOI: 10.1243/09544054JEM572.

[31] Costa, S.F., Duarte, F.M., Covas, J.A. (2015). Thermal conditions affecting heat transfer in FDM/FFE: a contribution towards the numerical modelling of the process, Virtual Phys. Prototyp., 10(1), pp. 35-46.

[32] Zhang, J., Wang, X.Z., Yu, W.W., Deng, Y.H. (2017). Numerical investigation of the influence of process conditions on the temperature variation in fused deposition modeling, Mater. Des., 130, pp. 59-68.

[33] Li, H., Wang, T., Sun, J., Yu, Z. (2018). The effect of process parameters in fused deposition modelling on bonding degree and mechanical properties, Rapid Prototyp. J., 24(1), pp. 80-92, DOI: 10.1108/RPJ-06-2016-0090. 